organe besondere Eigenthümlichkeiten und ferner individuelle Verschiedenheiten bemerkbar machen, so zwar, dass sogar ein bestimmtes Versuchsindividuum zu verschiedenen Zeiten ein verschiedenes Verhalten aufweist.

\title{
Bemerkungen zu dem Aufsatz: \\ Ueber den Verlauf der die Pupille verengenden Nervenfasern im Gehirn ${ }^{1}$ ).
}

Von

\section{v. Hensen.}

Der eitirte Aufsatz enthält so grosse Unrichtigkeiten uber Angaben, welche von Völckers und mir ${ }^{2}$ ) herrühren, dass es nicht statthaft erscheint, dariiber zu schweigen.

1) Es wird von dem Autor fortwährend betont, wir bätten das von uns gefundene Centrum der Bewegung für die willkührlichen Augenmuskeln, deren es mehrere geben mag, in den dritten Ventrikel verlegt. Es ist jedoch sowohl in der citirten Arbeit selbst wie auch in einer international verständlichen Zeichnung als Lage des Centrums der Boden des Aquaeductus Sylvii bezeichnet. Die falsche Angabe des Autors wird von Bedeutung, weil er auf Grund derselben unseren Befund verwirft und dennoch unsere Ansicht, dass das erste Centrum der Oculomotoriuskern sei, denn dieser liegt an der bezeichneten Stelle, völlig theilt. Nicht diese sehon anatomisch so höchst wahrscheinlich gemachte Sache, sondern die Lage der Innervationscentren innerhalb des Oculomotoriuskerns hatten wir aufzufinden uns bemüht; gereizt wurden vor Allem die centralsten Enden der Oculomotorius w u rzeln.

2) Es wird uns vorgeworfen, wir hätten iibersehen, dass die gesetzten Verletzungen Gleichgewichtsstörungen und Zwangsbe-

1) Dr. W. Bechterew, Dies Archiv, Bd. XXXI, p, 60.

2) Gräfe's Archiv f. Ophthalmologie, 1878, Bd 24, p. 1. 
wegungen zur Folge hätten. Diese Behauptung ist unrichtig, denn wir haben S. 16 ausdrücklich betont, dass wir die betreffenden Erfahrungen (natürlich da, wo wir reizten, nicht am „Boden des dritten Ventrikels") als nicht hingehörigg gänzlich übergingen. Ausserdem haben diese Dinge mit der Untersuchung nichts zu thun, denn wenn der Muskel auf Reizung zuckt, ist es für die Frage des Centrums gleichgiiltig, ob er vorher ganz schlaff oder etwas contrahirt war. Gegen die fernliegende Möglichkeit, dass durch Erschlaffung eines Antagonisten Bewegung hätte entstehen können, sicherten wir uns durch Versuche an Muskeln, welche vom Auge abgetrennt worden waren.

3) Ferner wird uns vorgeworfen, dass wir mit Hülfe von Reizungen untersucht hätten. Abgesehen davon, dass für die Hauptaufgabe, die Auffindung des Accommodationscentrums, kein anderes Verfahren möglich war, ist der Vorwurf uiberhaupt nicht berechtigt. Schiff betont ja mit grösstem Recht, dass die Durchschneidung deshalb und insoweit die exacteste Untersuchungsmethode ist, weil noch restirende Functionen nicht von Bahnen, welche durchschnitten worden sind, allein abhängen können. Wie weit jedoch die Schnittwirkung sich in's Gewebe erstreckt, lässt sich bis jetzt ebensowenig wie die Ausbreitung der Wirkung eines Inductionsstromes völlig genau bestimmen. Letzterer ist aber für motorische Theile, wenn die Reizung positiven Erfolg hat, deshalb ein sehr empfehlenswerthes und unentbehrliches Hilfsmittel, weil der Versuch, soweit das Thier aushält, sich bis zum Ueberdruss wiederholen lässt, weil das gereizte Feld sowohl genau genug abgetastet als auch isolirt und weil die Intensität der Ströme auf das geringste noch wirksame Maass herabgebracht werden kann. Diese Bedingungen haben wir erfiullt und ge. wannen so Ansichten, an denen wir trotz jenes Widerspruchs festhalten.

4) Wenn vom Opticus noch eine andere Bahn zu dem von uns bezeichneten Iriscentrum führt, das übrigens nicht, wie wiederum fälschlich angegeben, am Boden, sondern an der Rückwand des dritten Ventrikels, d. h. an der vorderen Spitze des Oculomotoriuskerns liegt, schliesst dies die Existenz der von uns beiläufig aufgefundenen Bahn keineswegs aus. 